\title{
Design of Additively Manufactured Heatsinks for Power Electronics Thermal Management using Adjoint Level-set Topology Optimization
}

\author{
Pushpa Rajaguru², Manisekaran Santhanakrishnan ${ }^{1}$, Tim Tilford ${ }^{2}$, and Chris Bailey² \\ [1] Cranfield University, College Rd, Cranfield, Bedford MK43 OAL \\ [2] Computational Mechanics and Reliability Group, University of Greenwich, London SE10 9LS, UK \\ Telephone: +44(0)2083319768, and e-mail: p.rajaguru@gre.ac.uk
}

\begin{abstract}
This paper investigates the potential of using the Adjoint Level-set topological optimization approach for design of additively manufactured power electronics heat sinks. Additive manufacturing techniques are readily able to fabricate highly complex metal geometries. This capability could be translated into development of higher performance thermal management solutions if the design methodology to exploit this potential. This study attempts to investigate the ability of topology optimization to meet this requirement. This paper provides a brief review of the current state-of-the-art in the topological optimization field. An overview of the Adjoint Level-set method is presented along with details of the implemented framework. This framework is used to design power electronics heatsinks, considering a combination of materials and fluid flow rates. The analysis is multi-objective, simultaneously considering heat extraction and flow pressure difference. The heat flux into the heatsink is considered to be from two discrete heat fluxes representing active packages within the power module. The cooling channels developed by the topology optimization framework react to the position of the heat sources. Results demonstrating the capability for topological optimization to develop effective thermal management solution are presented. The primary conclusions for the study are that this is an area that is worth of further investigation. Significant challenges need to be addressed, particularly relating to the rapid increase in computational cost as flow rates increase, before this technology can be transitioned to commercial adoption.
\end{abstract}

Index Terms - Topology Optimization, Level-set method, Heat sink, Thermal diffusivity

\section{INTRODUCTION}

Additive manufacturing (AM) of metallic parts through techniques such as Selective Laser Sintering (SLS) / Selective Laser Melting (SLM) enables fabrication of complex structures in a rapid and cost effective manner. This capability can potentially be utilised to form micro/power electronics thermal management structures which exhibit performance and/or cost benefits over those formed using conventional manufacturing techniques. This raises the issue of how to design a structure able to effectively exploit this potential. Topological optimisation (TO) is a numerical technique which aims to determine the distribution of material within a defined volume that either minimises or maximises a defined performance metric. Designs developed by TO are often complex, non-intuitive and organic in shape. AM and TO are highly synergistic technologies. AM enables production of complex forms but at higher cost than traditional methods. AM is therefore most applicable where the benefits from the complexity of the form offset or outweigh the cost implications. TO enables development of designs with superior performance than those designed using conventional design approaches but which are difficult to manufacture using conventional techniques.

In this study a state-of-the-art TO approach based on the Adjoint Level-set approach has been utilized to design a heatsink for power electronics thermal management. Traditional heatsink design typically relies on rules-of-thumb or a parametric optimization studies to develop a cooling/heating channel arrangements. TO offers an alternative approach to design the heatsink. In essence, TO attempts to determine the arrangement of material within a defined design domain that best minimizes the specified objective. TO has been used for structural mechanics problems since its origins in the work of Bendsøe and Kikuchi [1]. Their approach is based on density method topology optimization (DMTO) and its use in problems involving fluid flow is relatively restricted. This restriction is due to complexity of the flow physics and associated boundary conditions and numerical stability challenges which arise when coupling optimization and flow analysis algorithms. The Levelset method (LSM) is an alternative approach for density method (DM) which has been applied to structural problems [2] since 2003. The LSM approach is more complex than DM but provides sharper capture of interfaces and precludes intermaterial (grey) regions. Other classical heatsink design approach include of the parametric optimization to maximize the overall thermal resistance and minimize the heatsink mass, see Bornoff 
et al [3]. This work adopts a continuous adjoint approach for accurate shape sensitivity evaluation in combination with Hamilton Jacobi equation based level-set method. The application of this approach for the analysis of heatsink is novel, providing superior designs with accurate solid-fluid interface definition. The implemented LSM TO framework utilizes the ersatz material mapping for different materials. The optimization objective is comprised of heat flux maximization and pressure drop minimization components. Variation of the relative weighting of these components will enable trade-off analyses to be performed.

\section{ADJOINT LEVEL SET TOPOLOGY OPTIMISATION}

The Level-set numerical approach adopted for this work is based on ersatz material approximation and on the solution of a Hamilton-Jacobi equation to convect the level sets, (see Deng et al [2]). For heatsink design inside a fluid channel, in order to distinguish between fluid and structure in design domain, signed distance function (SDF) is used to define the Level-set function, with a negative SDF $(\psi)$ considered to represent the solid regions and a positive SDF is considered to represent the fluid regions as illustrated in Fig. 1. This is enforced by the ersatz material mapping approach using a Heaviside function (see Allaire et al., [3]).

$$
\psi=\left\{\begin{array}{c}
=0 \forall x \in \partial \Omega \text { (boundary) } \\
>0 \forall x \in \Omega^{+}(\text {Fluid region) } \\
<0 \forall x \in \Omega^{-} \text {(Solid region) }
\end{array}\right.
$$

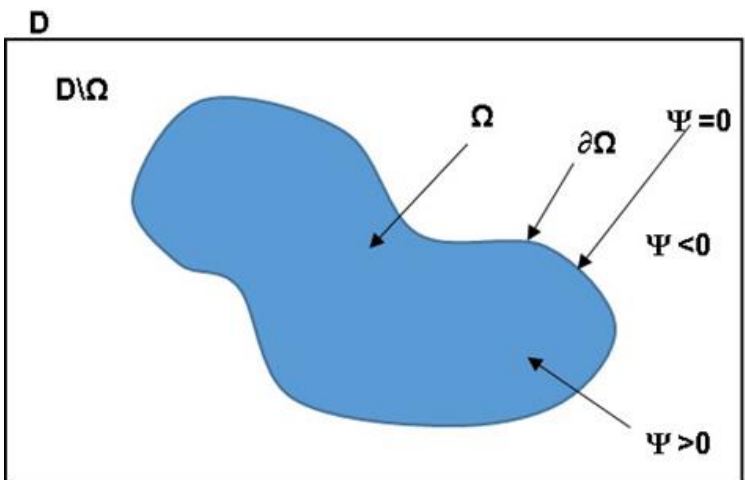

Fig. 1. Design domain and level set function

The level set function is defined within the design domain. The governing equations for this problem consists of NavierStokes equation in incompressible flow (Equations (2) and (3)) and energy equation (Equation (4)). Energy equation has a temperature dependent heat sink term. This means that fluid heat extraction rate is proportional to fluid temperature instead of having uniform fluid heat extraction rate.

$$
\begin{gathered}
\rho_{\gamma}(\boldsymbol{u} . \nabla \boldsymbol{u})=-\nabla p+\nabla \cdot\left\{\mu_{\gamma}\left\{\nabla \boldsymbol{u}+(\nabla \boldsymbol{u})^{T}\right\}\right\}-\alpha u \\
\rho_{\gamma}(\nabla \cdot \boldsymbol{u})=0
\end{gathered}
$$

$$
\begin{gathered}
\rho_{\gamma} C_{p \gamma}(\boldsymbol{u} . \nabla T)=\nabla \cdot\left(k_{\gamma} \nabla T\right)+Q T \\
Q=Q_{o}(1-H) T
\end{gathered}
$$

The Brinkman porosity term, $\alpha$, is used to differentiate the solid and fluid region within the design domain and it is modelled as given in Equation (6). ' $\mathrm{H}$ ' is the Heaviside function, which is equal to unity when $\psi$ is positive, equal to zero when $\psi$ is negative with a smoothly transition between values to enable differentiability. The value of $\alpha_{\max }$ equals to $1 \times 10^{5}$ and $\alpha_{\min }$ equals to $1 \times 10^{-2}$.

$$
\alpha=\alpha_{\max } *(1-H)+\alpha_{\min }
$$

The smoothed Heaviside function is defined as

$$
\begin{aligned}
& 0 \quad \psi \leq-h \\
& \begin{aligned}
H(\psi)=\frac{1}{2}+\frac{15}{16}\left(\frac{\psi}{h}\right)-\frac{5}{8}\left(\frac{\psi}{h}\right)^{3}+\frac{3}{16}\left(\frac{\psi}{h}\right)^{5} \quad-h<\psi \leq h \\
\psi \\
\psi>h
\end{aligned}
\end{aligned}
$$

where $h$ is the support size, i.e. in numerical computation, $h$ is the element size. The material properties used in the thermofluidic analysis are correlated to the Heaviside function. Region where Heaviside function becomes zero is considered as solid region, where heat-extraction is specified. Thermal properties of solid will be the same as fluid as in Table I. Subscript $s$ and $f$ in material properties correspond to solid and fluid properties.

TABLE I

MATERIAL PROPERTY FUNCTIONS

\begin{tabular}{lll}
\hline \multicolumn{1}{c}{ Function } & Quantity & Unit \\
\hline$\rho_{\gamma}=\left(\left(\rho_{\mathrm{s}}-\rho_{\mathrm{f}}\right) \cdot(1-\mathrm{H})\right)+\rho_{\mathrm{f}}$ & Density & $\mathrm{Kg} \cdot \mathrm{M}^{-3}$ \\
$C_{p \gamma=}\left(\left(\mathrm{C}_{\mathrm{ps}}-\mathrm{C}_{\mathrm{p}}\right) \cdot(1-\mathrm{H})\right)+\mathrm{C}_{\mathrm{pf}}$ & Specific heat & $\mathrm{M} \cdot \mathrm{s}^{-1}$ \\
$k_{\gamma}=\left(\left(\mathrm{k}_{\mathrm{s}}-\mathrm{k}_{\mathrm{f}}\right) \cdot(1-\mathrm{H})\right)+\mathrm{k}_{\mathrm{f}}$ & Thermal & $\mathrm{W} \cdot \mathrm{m}^{-1} \mathrm{~K}^{-1}$ \\
& conductivity & \\
$\mu_{\gamma}=\left(\mu_{\mathrm{s}}-\mu_{\mathrm{f}}\right) \cdot(1-\mathrm{H})+\mu_{\mathrm{f}}$ & Viscosity & $\mathrm{Pa} \cdot \mathrm{s}$
\end{tabular}

The next step is to determine how to change the material distribution to minimize the objective. This is achieved by propagating the level set function using a Hamilton Jacobi equation (equation (8)) in the decreasing direction of objective function. This is ensured by choosing the velocity of propagation along a fictional time step equal to the shape sensitivity of the Lagrangian of the problem (equation (9)).

$$
\begin{gathered}
\frac{\partial \psi}{\partial t}=V_{n}|\nabla \psi| \\
V_{n}=F^{\prime}(\Omega)+\lambda+\Lambda\left(\int_{\Omega} H(\psi) d \Omega-V * V_{\Omega}\right)
\end{gathered}
$$

Where, $\mathrm{F}$ is the time derivative of the shape sensitivity, $\lambda$ is the Lagrange multiplier, $\Lambda$ is the volume penalty factor (or penalization parameter) and $\mathrm{V}$ is the volume constraint of the material. This work is based on augmented Lagrangian approach and in this Lagrange multiplier and volume penalty factor are updated as follows. 


$$
\begin{gathered}
\lambda_{k}=\lambda_{k-1}-\Lambda_{k-1}\left(\int_{\Omega} H(\psi) d \Omega-V * V_{\Omega}\right) \\
\Lambda_{k}=\frac{1}{\beta} \Lambda_{k-1}, \quad \beta \in(0,1)
\end{gathered}
$$

The initial values of Lagrange multiplier, $\lambda$, volume penalty factor, $\Lambda$, and $\beta$ are user defined. The Level-sets and corresponding material distribution are advanced in a series of time steps with the Hamilton Jacobi equation solved using an explicit first order upwind scheme on a Cartesian grid, (see Allaire et al[4]). As the Level-sets are marched in time their gradients can become steep or slant which will lead to inaccuracy in interface boundary prediction. To combat this, Level-set re-initialization is performed on a regular basis. This is achieved by solving the Eikonal equation (Sussman et al., [5]).

The Level-set framework is augmented by adoption of a continuous adjoint method for shape-sensitivity calculations. The following is an overview of the numerical optimization framework implemented and utilized for the design studies described subsequently. The adjoint level set (ALS) method has been developed by Othmer [6] for laminar fluid flow problems and by Kontoleontos et al [7] for turbulent NS equation coupled with an energy equation. Adjoint based method is identified as method of choice for the computation of sensitivities in level set topology optimization since primary future of topology optimization is computation of the topological sensitivities. The objective function is comprised of terms relating to heat exchange and pumping power coupled with suitable weighting factors as given in equation 12 . The temperature difference and total pressure difference terms are calculated as per equations 13 and 14 respectively, I.e. The objective function $\mathrm{F}$ which is in the shape sensitivity (Equation (9)) analysis correspond to weighted combination of $\Delta \mathrm{T}$ (the function of average temperature difference between inlet and outlet boundary) and $\Delta \mathrm{P}$ (The average pressure difference between the inlet and outlet boundary). These weights characterizes the relative important of the individual objective function. In this study both objectives has equal priorities, hence the weighting factors $f_{1}$ and $f_{2}$ are kept as 1 .

$$
\begin{gathered}
F=-f_{1} \Delta T+f_{2} \Delta \mathrm{P} \\
\Delta T=\int_{\text {Inlet }} T \boldsymbol{u} . n d A-\int_{\text {Outlet }} T \boldsymbol{u} \cdot n d A \\
\Delta \mathrm{P}=\int_{\text {Inlet }}\left(p+0.5 \rho u^{2}\right) \boldsymbol{u} \cdot n d A \\
-\int_{\text {Outlet }}\left(p+0.5 \rho \boldsymbol{u}^{2}\right) \boldsymbol{u} \cdot n d A
\end{gathered}
$$

The optimization is performed subject to constraints, state equations $2-4$, and a volume constraint given in equation 15 .

$$
\int_{\Omega} H(\Psi) d \Omega \leq V * V_{\Omega}
$$

Taking residues of continuity, momentum and energy equations (Equations (2)-(4)) as $R_{p}, R_{u}$ and $R_{T}$, the augmented Lagrangian of this problem can be written as,

$$
L_{\text {aug }}=F+\int_{\Omega} q R_{p} d \Omega+\int_{\Omega} \boldsymbol{w} R_{\boldsymbol{u}} d \Omega+\int_{\Omega} T \hat{a} R_{T} d \Omega
$$

Where $q, \boldsymbol{w}$, and $T \hat{a}$ are the Lagrangian multipliers or adjoint variables for pressure, velocity vector and temperature to satisfy the state continuity, momentum and Energy equations. By expanding and using Gauss divergence theorem of the variation of Augmented Lagrangian with respect to porosity variable $\alpha$, adjoint equations are derived by eliminating all surface and volume integrals which depends on $\frac{\partial p}{\partial \alpha}, \frac{\partial u}{\partial \alpha}$ and $\frac{\partial T}{\partial \propto}$. For further details see Othmer [6] and Kontoleontos et al [7].

The adjoint Navier-Stokes and heat conduction equations can be written as:

$$
\begin{gathered}
\rho_{\gamma}((\nabla \boldsymbol{w} \cdot \boldsymbol{u})+(\boldsymbol{u} \cdot \nabla) \boldsymbol{w})=-\nabla q+ \\
\nabla \cdot\left\{\mu_{\gamma}\left\{\nabla \boldsymbol{w}+(\nabla \boldsymbol{w})^{T}\right\}\right\}-\alpha \boldsymbol{w}+\rho_{\gamma} C_{p \gamma} T \nabla T \hat{a} \\
\rho_{\gamma}(\nabla \cdot \boldsymbol{w})=0 \\
\rho_{\gamma} C_{p \gamma}(\boldsymbol{u} . \nabla T \hat{a})=-\nabla \cdot\left(k_{\gamma} \nabla T \hat{a}\right)-Q T \hat{a}
\end{gathered}
$$

Adjoint boundary conditions are as follows

$$
\begin{aligned}
& \text { Wall } \quad \boldsymbol{w}=0 \\
& T \hat{a}=0 \\
& \frac{\left(\mu_{\gamma}\left(\nabla \boldsymbol{w}+(\nabla \boldsymbol{w})^{T}\right)-q \boldsymbol{I}\right) n}{\rho_{\gamma}} \\
& =-(\boldsymbol{u} \cdot n) \boldsymbol{w}-(\boldsymbol{u} \cdot \boldsymbol{w}) n \\
& -C_{p \gamma}(T T \hat{a})-\frac{\partial F}{\partial \boldsymbol{u}} \\
& \left(k_{\gamma} \nabla T \hat{a}\right) n=-\rho_{\gamma} C_{p \gamma}(\boldsymbol{u} \cdot n) T \hat{a}-\frac{\partial F}{\partial T} \\
& \boldsymbol{w}_{t}=0 \\
& T \hat{a}=0 \\
& \boldsymbol{w} \cdot n=-\frac{\partial F}{\partial p}
\end{aligned}
$$

Since the objectives used in this study are surface integrated objectives, the influence of objective is only felt in the boundary conditions of adjoint equations which are given in equations (23 and 27). No slip boundary condition were also imposed on the wall of the boundary for flow equations (Equation (21)). The time derivative of shape sensitivity can then be calculated using:

$$
F^{\prime}(\Omega)=-\propto_{\max }(\boldsymbol{u} \cdot \boldsymbol{w}+T \cdot T \hat{a})
$$

\section{APPLICATION TO HEATSINK DESIGN}

The numerical framework outlined in the previous section has been applied to study a simplified but practical heatsink design. The geometry, as outlined in Fig. 2, is formed of an inlet section, 
L1 in length, W1 in width and height $\mathrm{H}$. The design domain extends from the inlet section with length L2, width W2 and height $\mathrm{H}$. This is $1 / 2$ of actual domain which is rectangular cuboid in shape. A heat flux extraction, Q, is assumed to be zero on the solid regions, instead boundary heat flux is applied to mimic heat flux from two square shaped chips on the bottom surface of the domain as in Fig 3. The length of two identical square shaped chips is $20 \mathrm{~mm}$. The distance between the two chips sources in the flow direction is $60 \mathrm{~mm}$. The symmetry along the central plane and wall boundary with no slip conditions on all other surfaces are also imposed as in Fig 2.

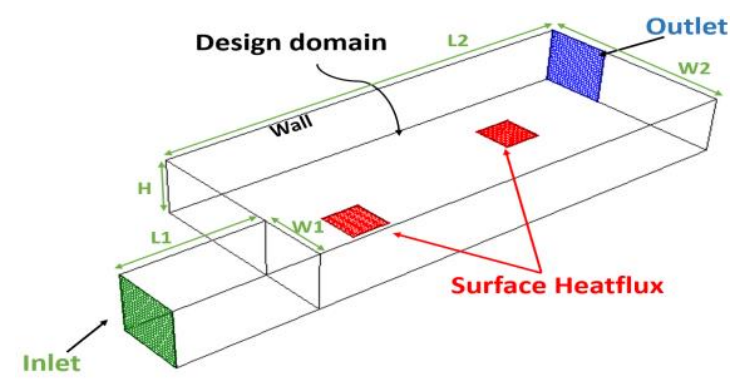

Fig. 2. Illustration of domain with two square shaped chips $(20 \mathrm{~mm} \times 20 \mathrm{~mm})$ with boundary heatflux $\left(150000 \mathrm{~W} / \mathrm{m}^{2} . \mathrm{s}\right)$ on the surfaces

A constant flow rate with inlet temperature of $288{ }^{\circ} \mathrm{k}$ is defined and correlated to a Reynolds number. Geometric parameters are given in Table III. The design domain is constrained to the main section of the geometry - i.e. optimization is not carried out in the inlet section. The COMSOL Multiphysics [8] Finite Element Analysis package has been used to solve the governing equations. MATLAB based finite difference code is used for level set advection and reinitialization of level-sets. These two modules are coupled and executed repeatedly till convergence as described in Santhanakrishnan et al [9]. A flow chart outlining the topology optimization methodology is illustrated in Fig. 3, with steps contained within the left dashed line box are carried out in COMSOL Multiphysics software and the steps in right dashed line box are carried out in MATLAB Livelink.

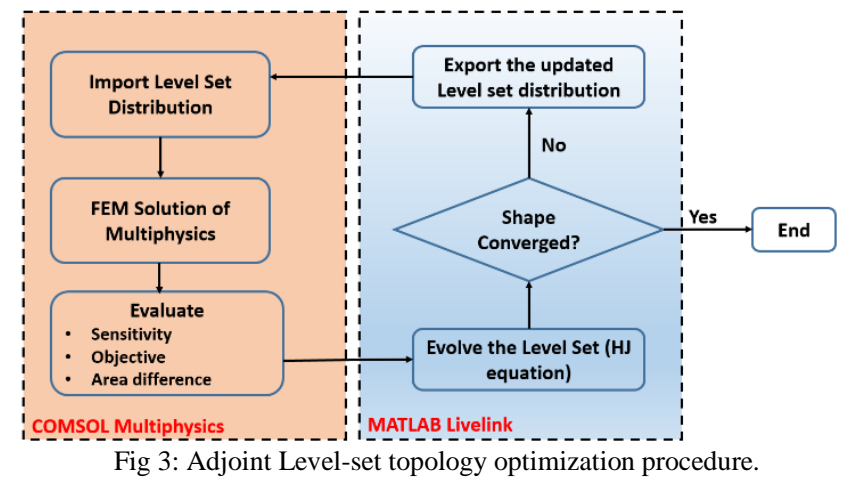

Topological optimization of the heatsink has been performed for 2 solid materials and 2 fluids. The material copper is highly applicable for electronics thermal management while the polymer material is studied out of academic interest rather than practical applicability. Copper is selected as it is commonly used for heatsink structures. Selective laser sintering of additive manufacturing enables the production of complex optimized shapes. Polymer (Heinle and Drummer [10]) is selected for interest, to see how optimized shapes compare with those of higher conductivity materials. The material property values used are given in Table II. The material property values used here are sourced from literature and are indicative rather than relating to a specific material formulation. Glycol is considered as the working fluid as its viscosity is slightly higher than the viscosity of water. Comsol takes very large time (>20hrs) to solve the state and adjoint equation for a low viscosity fluid like water. The viscosity of glycol was considered to be $0.0161 \mathrm{~Pa}$.s.

The fluid volume constraint was considered to be $45 \%$ of design domain volume - i.e. $55 \%$ of the design domain is solid and the remainder is fluid. The optimization of 2 different fluidsolid combinations are performed at a Reynolds number 19 and 38 since choosing higher Reynolds number leads to higher computational time to solve the state and adjoint equations. Each of the simulation is progressed to a fully converged state with run time of 73.2 hours on a 12 Xeon core workstation. Convergence plot of copper-glycol is shown in Figure 4. Optimisation starts with initial level set distribution as in Fig 5(a). The initial level set distribution consists of fin shaped solid distribution on a thick plate $(6 \mathrm{~mm})$. The square shaped (13.23mm length) fins with depth of $26 \mathrm{~mm}$ are arranged uniformly across the domain as in Fig 5(a).

TABLE II MATERIAL PROPERTY PARAMETERS

\begin{tabular}{|c|c|c|c|c|}
\hline Material & $\begin{array}{c}\text { Density } \\
\left(\mathrm{Kg} \cdot \mathrm{M}^{-3}\right)\end{array}$ & $\begin{array}{c}\text { Specific heat } \\
\text { capacity } \\
\left(\mathrm{J} \cdot \mathrm{Kg}^{-1} \cdot \mathrm{K}^{-1}\right)\end{array}$ & $\begin{array}{c}\text { Thermal } \\
\text { conductivity } \\
\left(\mathrm{W} \cdot \mathrm{M}^{-1} \cdot \mathrm{K}^{-1}\right)\end{array}$ & $\begin{array}{c}\text { Thermal } \\
\text { Diffusivity } \\
\left(\mathrm{M}^{2} \mathrm{~S}^{-1}\right)\end{array}$ \\
\hline Glycol & 1113.2 & 2470.2 & 0.258 & $9.382 \mathrm{e}-4$ \\
\hline Copper & 8960 & 385 & 400 & $1.160 \mathrm{e}-4$ \\
\hline Polymer & 850 & 500 & 6 & $1.412 \mathrm{e}-5$ \\
\hline
\end{tabular}

TABLE III GEOMETRIC PARAMETERS

TABLE III GEOMETRIC PARAMETERS
\begin{tabular}{|c|c|c|c|}
\hline Parameter & Symbol & Value & Unit \\
\hline Inlet section length & L1 & 0.06 & $\mathrm{~m}$ \\
\hline Main section length & L2 & 0.2 & $\mathrm{~m}$ \\
\hline Inlet section width & W1 & 0.03 & $\mathrm{~m}$ \\
\hline Main section width & W2 & 0.09 & $\mathrm{~m}$ \\
\hline Height & Height & 0.03 & $\mathrm{~m}$ \\
\hline Boundary Heat flux & $\mathrm{Q}$ & 150000 & $\mathrm{~W} \cdot \mathrm{m}^{-2} \cdot \mathrm{s}^{-1}$ \\
\hline
\end{tabular}

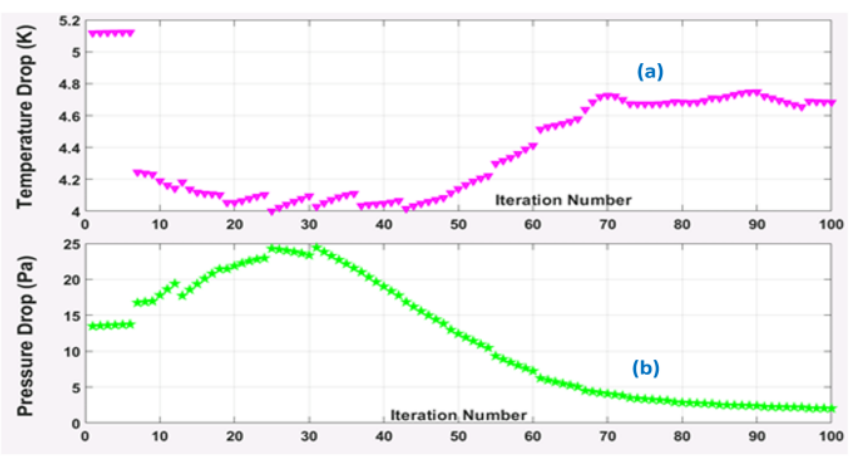

Fig 4. (a) Average temperature drop between the inlet and outlet boundary against iteration, (b) Average pressure drop between the inlet and the outlet boundary against iteration 


\section{IV.}

RESULTS

Figure 5(a) illustrate the initial copper heatsink design within the glycol fluid channel and the figure 5(b) is the optimized copper heatsink shape. In Figure 6(a), the pressure distribution in the domain for initial fin shaped heatsink design and 6(b) is the pressure distribution in the domain for optimized heatsink shape for copper/glycol combination. Similarly the Figure 7 displays the temperature distribution in the domain for initial heatsink design and optimized heatsink design. Figure 8(a) is the temperature distribution plot in the domain for optimized copper heatsink design and 8(b) is the optimized polymer heatsink design within the glycol fluid channel. Tables IV and V list the maximum temperature and maximum pressure in the domain for initial and optimized heatsink shape for various solid material properties and Reynold numbers. Table VI and VII list the average temperature drop and average pressure drop between inlet and outlet for initial and optimized heatsink shape for various solid material properties and Reynold number.

Two solid materials (copper and polymer) were compared for their effectiveness on heat transfer and pressure drop. Based on the Table IV and V, it is clear that the performance of the polymer materials is, as expected, far poorer than the copper material. The TO algorithm attempts to compensate for this by tolerating a higher pressure drop. The optimized designs, illustrated in figure 8 , show that algorithm is capable of developing designs that consider the heat source location and also the fabrication material while developing the design.
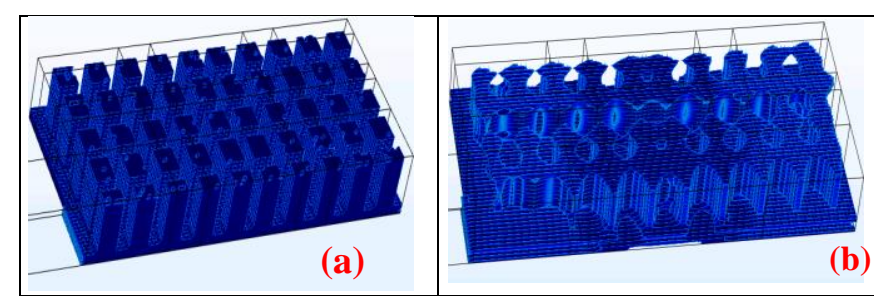

Fig. 5. (a) Initial fin shaped copper heatsink in glycol fluid channel (b) Optimized copper heatsink in glycol fluid channel at flow Reynold number $=19$

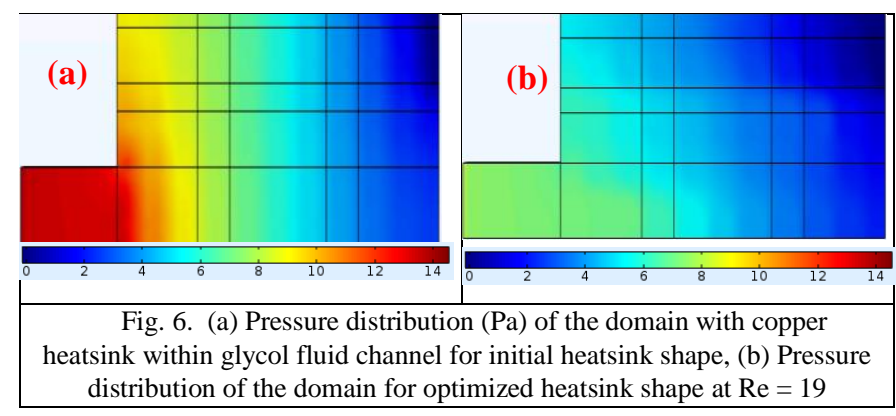

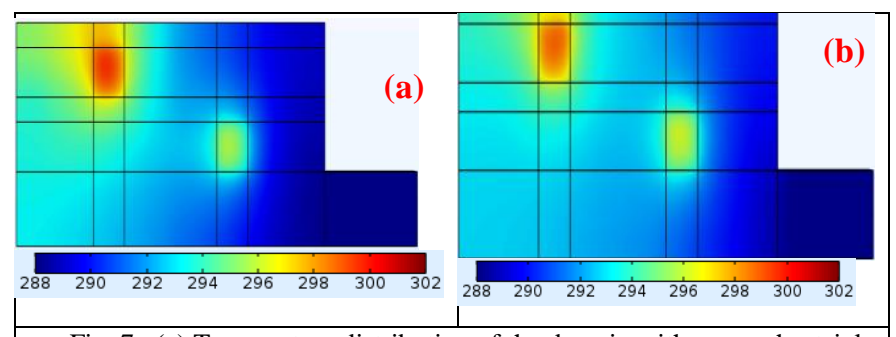

Fig. 7. (a) Temperature distribution of the domain with copper heatsink within glycol fluid channel for initial fin heatsink shape, (b) Temperature distribution of the domain for optimized heatsink shape at $\mathrm{Re}=19$
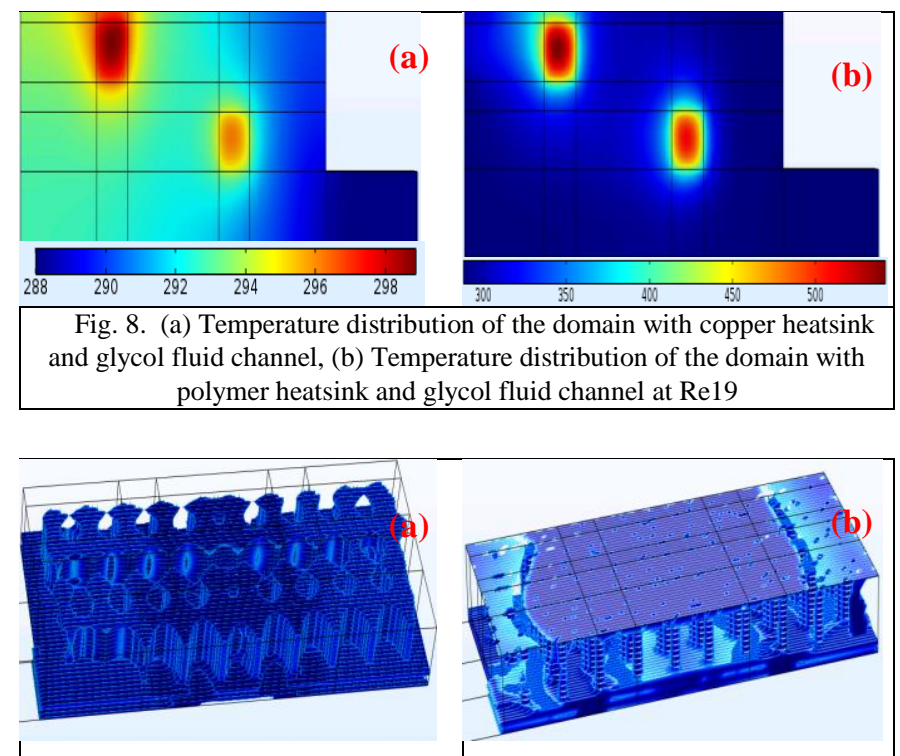

Fig. 8. (a) Optimized heatsink shape for copper and glycol fluid combination, (b) Optimized heatsink shape for polymer and glycol fluid combination at $\mathrm{Re}=19$

TABLE IV: MAXIMUM TEMPERATURE IN THE DOMAIN

\begin{tabular}{|c|c|c|c|c|}
\hline $\begin{array}{c}\text { Reynold } \\
\text { Number }\end{array}$ & $\begin{array}{c}\text { Heatsink } \\
\text { Material/ } \\
\text { Fluid }\end{array}$ & $\begin{array}{c}\text { Initial } \\
\text { Design } \\
\text { Maximum } \\
\text { Temperatu } \\
\text { re (K) }\end{array}$ & $\begin{array}{c}\text { Optimized } \\
\text { Design } \\
\text { Maximum } \\
\text { Temperature } \\
(\mathrm{K})\end{array}$ & $\begin{array}{c}\text { Percentage } \\
(\%) \\
\text { Improvement }\end{array}$ \\
\hline \multirow{2}{*}{19} & $\begin{array}{c}\text { Copper/ } \\
\text { Glycol }\end{array}$ & 301.67 & 298.86 & 0.93 \\
\cline { 2 - 5 } & $\begin{array}{c}\text { Polymer/ } \\
\text { Glycol }\end{array}$ & 516.17 & 541.82 & -4.97 \\
\hline 38 & $\begin{array}{c}\text { Copper/ } \\
\text { Glycol }\end{array}$ & 296.68 & 295.9 & 0.26 \\
\cline { 2 - 5 } & $\begin{array}{c}\text { Polymer/ } \\
\text { Glycol }\end{array}$ & 491.48 & 527.15 & -7.32 \\
\hline
\end{tabular}

TABLE V: MAXIMUM PRESSURE IN THE DOMAIN

\begin{tabular}{|c|c|c|c|c|}
\hline $\begin{array}{c}\text { Reynold } \\
\text { Number }\end{array}$ & $\begin{array}{c}\text { Heatsink } \\
\text { Material/ Fluid }\end{array}$ & $\begin{array}{c}\text { Initial } \\
\text { Design } \\
\text { Maximum } \\
\text { Pressure } \\
(\mathrm{Pa})\end{array}$ & $\begin{array}{c}\text { Optimized } \\
\text { Design } \\
\text { Maximum } \\
\text { Pressure } \\
(\mathrm{Pa})\end{array}$ & $\begin{array}{c}\text { Percentage } \\
(\%) \\
\text { Improvement }\end{array}$ \\
\hline \multirow{2}{*}{19} & Copper/ Glycol & 14.54 & 8.38 & 42.09 \\
\cline { 2 - 5 } & Polymer/ Glycol & 14.03 & 9.40 & 31.58 \\
\hline \multirow{2}{*}{38} & Copper/ Glycol & 31.06 & 16.96 & 45.40 \\
\cline { 2 - 5 } & Polymer/ Glycol & 29.28 & 19.49 & 33.44 \\
\hline
\end{tabular}


TABLE VI: AVERAGE TEMPERATURE (K) DROP BETWEEN INLET AND OUTLET

\begin{tabular}{|c|c|c|c|c|}
\hline $\begin{array}{c}\text { Reynold } \\
\text { Number }\end{array}$ & $\begin{array}{c}\text { Heatsink } \\
\text { Material/ } \\
\text { Fluid }\end{array}$ & $\begin{array}{c}\text { Initial Design } \\
\text { Average } \\
\text { Temperature } \\
\text { (K) drop }\end{array}$ & $\begin{array}{c}\text { Optimized } \\
\text { Design } \\
\text { Average } \\
\text { Temperature } \\
\text { (K) drop }\end{array}$ & $\begin{array}{c}\text { Percentage } \\
(\%) \\
\text { Improvemen } \\
\mathrm{t}\end{array}$ \\
\hline \multirow{2}{*}{38} & $\begin{array}{c}\text { Copper/ } \\
\text { Glycol }\end{array}$ & 5.12 & 4.41 & 13.87 \\
\cline { 2 - 5 } & $\begin{array}{c}\text { Polymer/ } \\
\text { Glycol }\end{array}$ & 8.85 & 8.41 & 4.97 \\
\hline & $\begin{array}{c}\text { Copper/ } \\
\text { Glycol }\end{array}$ & 2.55 & 2.16 & 15.29 \\
\cline { 2 - 6 } & $\begin{array}{c}\text { Polymer/ } \\
\text { Glycol }\end{array}$ & 5.38 & 4.72 & 12.27 \\
\hline
\end{tabular}

TABLE VII: AVERAGE PRESSURE (Pa) DROP BETWEEN INLET AND OUTLET

\begin{tabular}{|c|c|c|c|c|}
\hline $\begin{array}{l}\text { Reynold } \\
\text { Number }\end{array}$ & $\begin{array}{c}\text { Heatsink } \\
\text { Material/ } \\
\text { Fluid }\end{array}$ & $\begin{array}{c}\text { Initial } \\
\text { Design } \\
\text { Pressure } \\
(\mathrm{Pa}) \text { drop } \\
\end{array}$ & $\begin{array}{c}\text { Optimized } \\
\text { Design } \\
\text { Pressure }(\mathrm{Pa}) \\
\text { drop } \\
\end{array}$ & $\begin{array}{c}\text { Percentage } \\
(\%) \\
\text { Improvement }\end{array}$ \\
\hline \multirow[t]{2}{*}{19} & $\begin{array}{c}\text { Copper/ } \\
\text { Glycol }\end{array}$ & 13.48 & 7.24 & 46.29 \\
\hline & $\begin{array}{c}\text { Polymer/ } \\
\text { Glycol }\end{array}$ & 13.10 & 7.80 & 40.46 \\
\hline \multirow[t]{2}{*}{38} & $\begin{array}{c}\text { Copper/ } \\
\text { Glycol }\end{array}$ & 28.35 & 14.03 & 50.51 \\
\hline & $\begin{array}{c}\text { Polymer/ } \\
\text { Glycol }\end{array}$ & 27.12 & 16.79 & 38.09 \\
\hline
\end{tabular}

The optimized shape is affected by the initial level-set distribution, the initial value of Lagrange multiplier, volume penalty factor and its rate of increment. Maximum temperature in the domain for optimized polymer material heatsink is slightly higher than the maximum temperature observed in the domain with initial fin shaped heatsink as in the Table IV even though the average temperature drop (between inlet and outlet) decreasing from the initial shape to optimized shape. Hence additional objective of minimizing the maximum temperature of the domain also should be included in the objective vectors.

One of the limitation of topology optimisation by porosity approach is brought out in this study. TO ALS method leads to design which are un-feasible practically, however flow velocity isocontour helps to visualize the heatsink shape. In the LS method, extended finite element method (xFEM) geometric mapping, is more accurate for solid modelling, hence by using this method, practically feasible shapes can be obtained for internal flow problems. Since the solid is porous in nature, the reported total pressure drops will also be higher than the actual non-porous solid case. Kreissl and Maute [11] also reported about the pressure diffusion across the solids created by porosity approach. Increasing the Reynold number results in increment in heat removal from the domain, in contrast the pressure in the domain will increase due to porous nature of the heatsink design and the increment of fluid mass in the domain. Furthermore high Reynold number implies longer computational times. Hence design practitioner has to choose a suitable Reynold number, in order to trade off the temperature, pressure in the domain and the computational cost.

\section{CONCLUSIONS}

This paper presents a nascent approach for design of electronics thermal management structures which exploit the potential of additive manufacturing technologies. An adjoint level-set topological optimisation algorithm has been applied to design of a simplified heatsink geometry. The continuous adjoint method is used to calculate the shape sensitivity and the level-sets are re-initialised at regular intervals for accurate capture of solid-fluid interfaces. The effectiveness of the approach has been demonstrated. Results indicate that the approach is able to consider the package/heat source positioning and develop designs which outperform a standard heatsink design. Furthermore the results show that if solids thermal conductivity is higher, then higher heat recovery is possible. Increasing the fluid thermal diffusivity results in little improvement in heat recovery. The study also highlights the drawback of level-set optimization with porosity based solid modelling. While this technology is still very much in development, it should be considered as having potential to augment current thermal management design techniques, an approach able to exploit the benefits of additive manufacturing and to be a technology that may become increasingly important across a range of engineering design disciplines over the next few years.

\section{ACKNOWLEDGMENT}

Mani SanthanaKrishnan wish to acknowledge the University of Greenwich Vice Chancellor's scholarship scheme for providing the funding opportunity for this study.

\section{REFERENCES}

[1] M. Bendsoe, N. Kikuchi, Generating optimal topologies in structural design using a homogenization method, Comp. Meth. Appl. Mech. Eng., 71, pp. 197-224, 1988

[2] Y. Deng, Z. Liu, J. Wu, and Y. Wu, Topology optimization of steady Navier Stokes flow with body force, Computer Methods in Applied Mechanics and Engineering., 255, pp.306-321, 2013

[3] Bornoff, R., Subat, B., Wilson, J. Generative heatsink design for an automotive audio amplifier, 34th Annual Semiconductor thermal Measurement and Management Symposium, SEMI-THERM 2018 Proceedings, pp. 218-223, San Jose, CA

[4] G. Allaire, F. Jouve, and A. M. Toader, Structural optimization using sensitivity analysis and a level-set method. Journal of Computational Physics, 194(1), pp.363-393, 2004.

[5] M. Sussman, P. Smereka and S. Osher, A level set approach for computing solutions to incompressible two phase flow, Journal of computational physics, vol. 114, pp. 146-159, 1994

[6] C Othmer, A continuous adjoint formulation for the computation of topological and surface sensitivities of ducted flows, International Journal of Numerical Methods in Fluids, 58, 861-877, 2005.

[7] E. A. Kontoleontos, E.M. Papoutsis-Kiachagias, A.S. Zymaris et.al. Adjoint based constrained topology optimization for viscous flows, including heat transfer, Engineering Optimizations, 45(8), 941-961, 2013.

[8] https://www.comsol.com [page last accessed $23^{\text {rd }}$ Aug 2018]

[9] M. Santhanakrishnan, T. Tilford, and C. Bailey, Level set based Topology optimisation of convectively cooled heat sinks, Proceeding of Comsol conference, Rotterdam, Netherlands, 2017.

[10] Heinle, C., Drummer, D., Potential of thermally conductive polymers for the cooling of mechatronic parts. Physics Procedia 5, pp735-744, 2010.

[11]S. Kreissl, and K. Maute, Level set based fluid topology optimization using the extended finite element method. Structural and Multidisciplinary Optimization, 46(3), pp.311-326, 2012. 